\title{
Is there exocrine pancreatic dysfunction in insulin resistance?
}

\author{
Saliha YILDIZ ${ }^{1}$, Ahmet Ufuk Komuroglu ${ }^{1}$, Murat ALAY ${ }^{1}$, and Gulcin Miyase SONMEZ ${ }^{1}$ \\ ${ }^{1}$ Van Yuzuncu Yil Universitesi
}

November 15, 2020

\begin{abstract}
Introduction: The aim of our study is to determine whether insulin resistance has any effect on pancreatic exocrine function in people with insulin resistance. Method: The study included 43 insulin resistant cases with HOMA-IR[?]2.5 and 43 controls (HOMA-IR <2.5.) without any disease, pregnancy. Fasting blood glucose, insulin, HbA1c, total cholesterol, triglyceride, HDL, LDL, creatinine, ALT, AST, Adiponectin, Leptin, pancreatic amylase, lipase were studied in both groups. Results: Statistically, both groups were similar in respect to gender and age (p: 0.25, 0.11, respectively). Body Mass Index were significantly higher in the case group (p 0.00). Fecal Elastase-1 levels were significantly lower in the IR group (p: 0.00). Blood glucose, insulin and HbA1c levels were significantly higher in the IR group than in the control (p: 0.00, 0.00, 0.00, respectively). Leptin levels were significantly higher in the IR group compared to the controls (p: 0.01). In the Pearson correlation analysis in the group with insulin resistance, a significant positive relation (p: $0.022 \mathrm{r}$ : +0.34) was detected between HOMA-IR and Adiponectin. There was a significant negative relation between pancreatic amylase and HOMA-IR (p: 0.029, r: -0.33), a significant negative relation between Fecal Elastase-1 and Adiponectin (p: 0.038, r: -0.31), a significant positive relation between Leptin and Adiponectin (p : 0.00, r: 0.59). Conclusion: Fecal Elastase -1 level decreased markedly in patients with insulin resistance, showing pancreatic exocrine dysfunction.
\end{abstract}

\section{Hosted file}

Is there exocrine pancreatic.pdf available at https://authorea.com/users/375860/articles/ 493050-is-there-exocrine-pancreatic-dysfunction-in-insulin-resistance

\section{Hosted file}

Table1.pdf available at https://authorea.com/users/375860/articles/493050-is-there-exocrinepancreatic-dysfunction-in-insulin-resistance 